\title{
Carotid Stenosis and Skin Cancer in the Surgical Incision Area
}

\section{Mustafa Karacelik}

Department of Pediatric Cardiac Surgery, Dr. BehçetUz Children's Hospital, Izmir, Turkey

*Corresponding author: Mustafa Karacelik, Department of Pediatric Cardiac Surgery, Dr. BehçetUz Children's Hospital, Izmir, Turkey, Tel: +90 5323354344 ; Fax: +90-232-364 7191; E-mail: mkaracelik@hotmail.com

Rec date: October 15, 2014; Acc date: November 07, 2014; Pub date: November 09, 2014

Copyright: $\odot 2014$ Karacelik M. This is an open-access article distributed under the terms of the Creative Commons Attribution License, which permits unrestricted use, distribution, and reproduction in any medium, provided the original author and source are credited.

\begin{abstract}
72-years-old male patient was admitted to our clinic with a diagnosis of transient ischemic attack. A mildly hemorrhagic lesion diagnosed by basosquamous cell carcinoma was detected. Carotid stent was implanted into carotid artery. Possibility of malignancy in these types of lesions located in the surgical incision area in patients with advanced aged should always be considered, and endovascular treatment options should be preferred instead of surgery.
\end{abstract}

Keywords: Carotid stenosis; Skin cancer

\section{Introduction}

Advanced age and male sex should be taken into account for cardiovascular evaluation especially suspicion of malignity [1]. Risk factors for atherosclerotic carotid artery disease and basosquamous cell carcinoma of the head and neck region are similar. Possibility of malignancy in advanced age is crucial pathophysiology that has to be required for a cancer search by all clinician [2]. Treatment modality of such these pathologies could be modified from standard manner when they were detected in the same time. The purpose of the study was to discuss of the originality of the case and the relationship between carotid artery stenosis and skin cancer in the surgical incision area.

\section{Case Report}

72-years-old male patient was admitted to our clinic with a diagnosis of transient ischemic attack. 90\% stenosis of left external carotid artery and 99\% stenosis of left internal carotid artery were detected on angiography. The stable plaque was detected by Doppler ultrasonography. A carotid bruit was determined on the left side of the neck by auscultation and a mildly hemorrhagic and crusty lesion with dimensions of $1 \times 0.5 \times 0.2 \mathrm{~cm}$ located at $1 / 3$ middle portion of left sternocleidomastoid muscle was seen on physical examination. Carotid artery involvement was not detected by computerized tomography. The lesion was investigated with a biopsy with the suspicion of malignancy and basosquamous cell carcinoma (Figure 1, arrow) was detected. Carotid stent was implanted into carotid artery under embolic protection because there was a malignant lesion located in the surgical incision area. The patient is still under follow-up after the lesion was removed by plastic surgeon and radiotherapy and chemotherapy following it and the stent is observed open.

\section{Discussion}

Cote et al. conclude that patients with atherosclerotic carotid artery disease have risk factor(s) associated with squamous cell carcinoma, the rate of occult squamous cell carcinoma was not different from that found in the general population and routine screening of patients with atherosclerotic carotid artery disease with Doppler ultrasonography to detect occult squamous cell carcinoma is not warranted $[2,3]$.

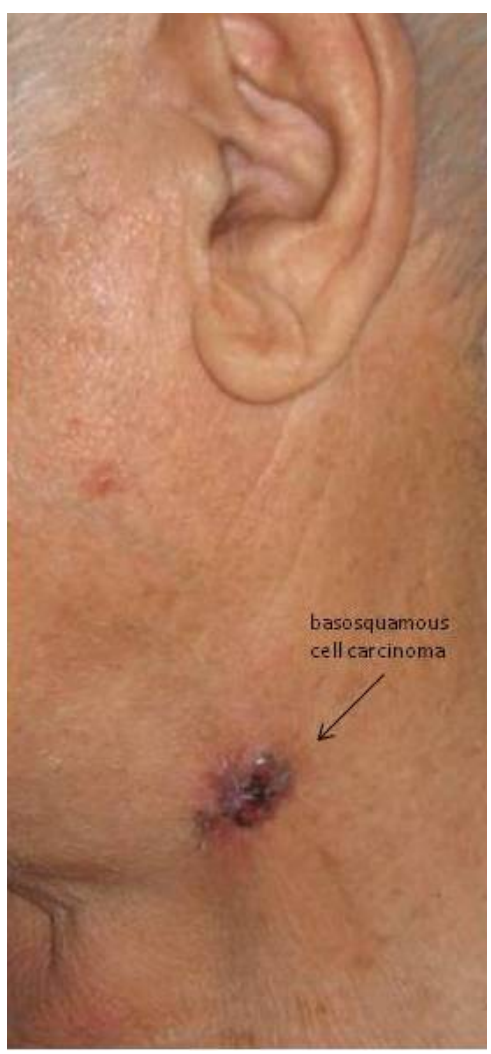

Figure 1: A mildly hemorrhagic and crusty lesion with dimensions of $1 \times 0.5 \times 0.2 \mathrm{~cm}$ located at $1 / 3$ middle portion of left sternocleidomastoid muscle

If the carotid artery involvement was not detected and possibility of malignancy in these types of lesions located in the surgical incision area in patients with advanced aged should always be considered, and 
Citation: Karacelik M (2014) Carotid Stenosis and Skin Cancer in the Surgical Incision Area. J Vasc Med Surg 2: 163. doi: $10.4172 / 2329-6925.1000163$

Page 2 of 2

endovascular treatment options should be preferred instead of surgery, for that reason, to avoid from metastases of the cancer.

\section{References}

1. Ciccone MM, Bilianou E, Balbarini A, Gesualdo M, Ghiadoni L, et al. (2013) Task force on: 'Early markers of atherosclerosis: influence of age and sex'. J Cardiovasc Med (Hagerstown) 14: 757-766.
2. Cote CR, Goff J, Barry P, Casler J (2001) The prevalence of occult carotid artery stenosis in patients with head and neck squamous cell carcinoma. Laryngoscope 111: 2214-2217.

3. Zhengang X, Colbert S, Brennan PA, Xue B, Yongfa Q, et al. (2013) Surgical management of metastases that involve the carotid artery in cases of primary squamous cell carcinoma of the head and neck. Int J Oral Maxillofac Surg 42: 440-445. 